\title{
Chemins de traverse pour le progrès génétique des cultures alimentaires africaines
}

Ce numéro thématique consacré à la sélection participative fait le point d'une évolution des idées et des pratiques de l'amélioration variétale engagée depuis plusieurs années au sein de la communauté scientifique francophone. On mesure ici tout le chemin parcouru depuis l'atelier du R3S (Réseau de recherche sur la résistance à la sécheresse) tenu à Bamako en 1991, où FrançoisNoël Reyniers parlait déjà, avec sa définition de « l'hydrosystème céréalier soudano-sahélien », de l'intérêt de conserver la diversité agricole pour faire face au risque climatique au Sahel. Mais ce qu'il est surtout intéressant de noter, c'est comment, depuis la prise en compte des facteurs variétaux de l'alimentation hydrique, les chercheurs ont croisé les chemins de la «biodiversité », notamment lors du Colloque sur la gestion des ressources génétiques (Bamako, 1997), pour ouvrir une nouvelle voie à l'amélioration des cultures en Afrique, valorisant, avec les paysans, les ressources génétiques locales.

Lun des ressorts de cette évolution réside dans l'épuisement du modèle linéaire descendant (top down) de l'innovation portée par les institutions publiques de recherche, de multiplication et de distribution des semences. Ce modèle, endossé par les États africains après leur accession à la souveraineté, a permis à des filières agro-industrielles, comme celles de l'arachide et du cotonnier, de se développer de façon spectaculaire. Il n'en a jamais été de même pour les cultures alimentaires, faute peut-être de marchés régionaux porteurs et sécurisants. Mais est-ce la raison principale? Depuis une quinzaine d'années, la faiblesse des financements consacrés aux structures publiques de recherche et le manque d'intérêt du secteur privé pour prendre le relais, remettent en cause le modèle traditionnel de transfert en agriculture.

Un autre ressort de cette évolution tient à la pertinence sociale et économique insuffisante du matériel végétal "amélioré » créé et diffusé par les établissements publics dans une perspective trop optimiste (on le constate après coup!) d'intensification progressive de la production pour faire face à une demande alimentaire croissante. En effet, c'est sur ce secteur des cultures vivrières - mil et sorgho - dominantes dans la région soudano-sahélienne que les progrès génétiques pris en compte par les paysans ont été les plus faibles. Force a été de constater que cultures pures en rotation, semis à haute densité de cultivars à fort potentiel, apports coûteux d'engrais chimiques et d'herbicides ne trouvaient pas place dans des pratiques paysannes sous-tendues par l'aversion aux risques (climatiques et économiques) et la nécessité de subvenir sans à-coups aux besoins alimentaires familiaux. Ces stratégies d'amélioration ont donc fait fi de toutes les conditions environnementales tant de l'écologie des espèces cultivées que des us et usages des variétés par les populations. Même si l'on sait que le paysan africain est prêt à modifier rapidement son régime alimentaire s'il est en mesure de mieux remplir son grenier avec le matériel végétal proposé, il n'en demeure pas moins que les qualités organoleptiques, les caractéristiques multifonctionnelles des coproduits (feuilles, fanes, tiges, coques, etc.) et le comportement des produits après récolte pèsent suffisamment lourd dans l'opinion des utilisateurs pour que les chercheurs les prennent en compte dans leurs objectifs de sélection.

Enfin, le ressort le plus fort a sans doute été la prise de conscience progressive de la pertinence des pratiques paysannes de gestion des ressources génétiques. Celle-ci tient, d'une part, à la qualité d'adaptation des variétés-populations photopériodiques et, d'autre part, à l'existence de réseaux sociotechniques et d'échanges non marchands de matériel végétal au sein des lignages et des territoires. Ces réseaux permettent aux paysans d'entretenir cette biodiversité agricole de façon dynamique dans un renouvellement permanent des variétés dont le brassage favorise les recombinaisons génétiques pour créer à nouveau de la diversité.

Les chercheurs qui acceptent avec humilité de se confronter à ces savoirs profanes et de laisser de côté, l'espace d'un projet pluridisciplinaire et pluri-institutionnel, leur statut social de «savants », n'en sortent pas indemnes. Mais au-delà de ce point d'étape, il faut s'interroger sur la possibilité, au bout du chemin, de faire émerger des systèmes durables d'innovation, porteurs du progrès génétique, qui ne cassent pas les systèmes actuels de partage des savoirs et de «propriété collective » des résultats. Comment aborder l'agroécosystème du paysan africain comme un construit social qui fait naturellement appel à la biodiversité ? Sera-t-il possible dans ces sociétés agraires qui n'ont rien de traditionnelles d'éviter la marchandisation du vivant, la rupture entre les clercs et les profanes? Cette « utopie » proposée par ce collectif de chercheurs, de techniciens et d'agriculteurs ne peut laisser indifférents les spectateurs désabusés des agricultures modernes.

Jean-Pascal Pichot Agronome tropicaliste $<$ jeapichot@numericable.fr> 